CARTA AL EDITOR

Rev Chil Salud Pública 2020,

Vol 24(1): 74-75

\section{CULTURA DE MASCARILLAS CASERAS: DEBATE ENTRE LA EFICIENCIA Y EL USO POR LA POBLACIÓN DE UNA TECNOLOGÍA SANITARIA}

\author{
THE CULTURE OF HOMEMADE MASKS: DEBATE ABOUT THE \\ EFFICENCY AND USE OF SANITARY EQUIPMENT BY THE GENERAL \\ POPULATION
}

Cynthia Vergara-Maldonado Instituto de Salud Sexual y Reproductiva, Universidad Austral de Chile. Valdivia, Chile cynthia.vergara@uach.cl Recibido el 16-04-2020; Aceptado el 27-04-2020
Se han difundido una serie de recomendaciones en el contexto de la pandemia COVID-19 que incluyen un uso de mascarillas más generalizado para la población mundial sobre todo en lugares públicos. Inclusive se reconoce que el uso de mascaras de tela o caseras podrían ayudar a una respuesta global contra la enfermedad ${ }^{1}$. Sin embargo, se advierte la escasez de investigaciones con respecto a la eficacia. Es preciso considerar que la eficiencia de filtración de un virus en los tejidos de una máscara, la que depende de una variedad de factores: la estructura y composición de la tela, y el tamaño, velocidad, forma y propiedades físicas de las partículas a las que está expuesta ${ }^{2}$

Un estudio centrado en el virus de la influenza puso en tela la efectividad de las mascarillas contra virus y bacterias. Considerando el tamaño similar al virus SARS CoV-2, se parte de la premisa que el virus viajará en el aire de la misma manera que dichas partículas respiratorias. Pues bien, las máscaras quirúrgicas tuvieron tres veces más efectividad, inclusive que las más efectivas de las mascarillas caseras que por lo demás tuvieron mucho menos eficiencia de filtración debido a su material grueso y una alta caída de presión del material ${ }^{2}$. Por otro lado, observaciones durante el brote de SARS sugirieron que el doble enmascaramiento y otras prácticas aumentaron el riesgo de infección por humedad, difusión de líquidos y retención de patógenos 3 .

¿Qué hace que se recomiende el uso de máscaras caseras? Al parecer una medida de tipo distributiva-económica provisoria, que alude a una gestión desde las políticas tecno-sanitarias a favor de los grupos más críticos que ejercen la atención sanitaria. Es preciso reflexionar acerca de ise deja la decisión del uso de mascarillas a nuestra merced o a merced del mercado? y ¿cómo incorporamos el uso de una tecnología sanitaria, supeditada a profesionales sanitarios, en la población de países de Latinoamérica?

Para el uso correcto de la mascarilla pueden existir diferencias; países como los del continente asiático, más allá de la efectividad de las máscaras, han logrado una transferencia efectiva del uso de este dispositivo a sus habitantes por razones de tradición o contaminación ambiental ${ }^{4}$. OMS declara que el uso de solo mascarilla no es suficiente ${ }^{5}$. Lo anterior, nos invita a repensar la balanza sobre la utilización de dispositivos menos eficaces como la máscara casera versus medidas como el aislamiento social, el confinamiento y el lavado de manos con jabón.

Se propone dirigir el lente al uso correcto del dispositivo (mascarilla) lo que se podría convertir en un factor interesante, como una variable en la propagación del virus, según su uso en una determinada cultura, siendo las variables culturales aquellas que podrían marcar la diferencia en los contagios y la letalidad. 


\section{REFERENCIAS BIBLIOGRÁFICAS}

1. Infobae: [Internet]. Argentina :Infobae; OMS abre la puerta a un uso más generalizado de mascarillas para limitar la propagación. Reporte de Stephanie Nebehay en Ginebra y Andrea Shalal en Washington; Editado en español por Javier López de Lérida; 2020 Apr 3 [cited 2020 Apr 6]; [about 3 screens]. Available from: https:// www.infobae.com/america/agencias/2020/04/03/ oms-abre-la-puerta-a-un-uso-mas-generalizado-de-mascarillas-para-limitar-la-propagacion/

2. Davies, A., Thompson, K. A., Giri, K., Kafatos, G., Walker, J., \& Bennett, A. (2013). Testing the efficacy of homemade masks: would they protect in an influenza pandemic? Disaster Medicine and Public Health Preparedness, 7(4), 413-418. https://doi.org/10.1017/ dmp.2013.43 [cited 2020 Apr 6]

3. Li, Y., Wong, T., Chung, J., Guo, Y. P., Hy, J. Y., Guan, Y. T., Yao, L., Song, Q. W., \& Newton, E. (2006). In vivo protective performance of N95 respirator and surgical facemask. American Journal of Industrial Medicine, 49(12), 1056-1065. https://doi.org/10.1002/ ajim.20395[cited 2020 Apr 6];

4. Parraguez, M.¿Por qué los asiaticos usan mascarillas quirurgicas en publico? [Internet]. 2014 [citado el 15 de abril de 2020]; :p. 1. Disponible en: https://www. biobiochile.cl/noticias/2014/12/13/por-que-los-asiaticos-usan-mascaras-quirurgicas-en-publico.shtml

5. WHO: [Internet]. Ginebra: Who; Advice on the use of masks in the context of COVID-19. 2020 Apr 6 [cited 2020 Apr 7]; [about 2 screens]. Available from: https:// www.who.int/publications-detail/advice-on-the-useof-masks-in-the-community-during-home-care-andin-healthcare-settings-in-the-context-of-the-novel-coronavirus-(2019-ncov)-outbreak 